\title{
Formação do professor de educação física e as dificuldades no início de carreira em escolas de ensino básico ${ }^{1}$
}

\author{
Jairo Antônio da Paixão* \\ Yuri Windson Santos Barroso** \\ Glauber César Cruz Custódio***
}

\begin{abstract}
Resumo
A presente investigação teve como objetivo analisar as dificuldades encontradas pelo professor de Educação Física no início de carreira docente, atuante na educação básica. A partir de um estudo de campo, de cunho qualitativo, verificou-se que a formação inicial não proporcionou conhecimentos específicos suficientes para a atuação desse professor no início de carreira. Dentre as formas de aquisição desses conhecimentos, foram mencionadas leituras de artigos, capítulos de livros, visitas a sites e contatos com professores formados há mais tempo, atuantes na Educação Física escolar. Portanto, implementar as experiências vivenciadas pelos acadêmicos nos cursos de licenciatura em Educação Física é uma demanda que merece ser discutida e concretizada nos cursos de formação inicial.
\end{abstract}

Palavras-chave: Formação inicial; Educação Física; licenciatura; escola.

\section{Teacher training of physical education and initial difficulties in career start in high schools}

\begin{abstract}
This research aimed is aimed at analyzing the initial difficulties encountered by Physical Education teachers at the beginning of carrer in high schools. From a qualitative field of study, it was found that the initial training did not provide sufficient expertise for the performance of these professionals in the career beginning. Among the forms of acquisition of this knowledge, was mentioned readings of articles, books and visits to sites and contacts with trained teachers, active in that field of professional intervention for longer, which, in turn, have a larger luggage of experience. This situation leads to the conclusion that implementing the experiences lived by academics in licensure degree in Physical Education is a demand that deserves to be discussed and implemented in the initial training courses.
\end{abstract}

Keywords: Initial training; Physical Education; licensure; school.

\section{Introdução}

Prevaleceu até um determinado período, o senso comum de que, para ensinar, bastava conhecer o conteúdo a ser trabalhado. Essa forma de entendimento denotava uma ênfase no conhecimento advindo da experiência prática do professor no exercício da docência. No entanto, pesquisas, na área de formação de professores (GUARNIERI, 2005; TARDIF, 2011; PIMENTA, 2012), têm evidenciado que o aprendizado do trabalho docente resulta da articulação de diferentes saberes com que o sujeito vai estabelecendo contato, num processo que se inicia na fase de formação acadêmico-profissional, em que lhe serão fornecidos saberes científicos, pedagógicos. Somam-se aos referidos saberes, as experiências diretas com o fazer do próprio trabalho que serão fundamentais, pois, nesta instância, serão articulados e produzidos saberes essenciais à prática de intervenção do

\footnotetext{
*Endereço eletrônico: jairopaixao@ufv.br

***Endereço eletrônico: yuriwindson@yahoo.com.br

*** Endereço eletrônico: russincruz1304@hotmail.com
}

professor no decorrer de sua trajetória profissional (TARDIF, 2011).

Nem sempre o processo de aprendizagem profissional, que se inicia nos cursos de formação inicial, acontece de forma linear em termos de aplicação nas áreas específicas de atuação docente. Poder-se-iam citar, por exemplo, os professores que se encontram no início de carreira. Na maioria das vezes, como afirma Tardif (2011), as experiências pré-profissionais e o contato com os conhecimentos teóricos e técnicos configuram-se como referenciais disponíveis e eleitos para orientar as ações do professor recém-formado. A questão é que nem sempre os cursos de formação inicial vêm cumprindo o seu papel (LÜDKE; BOING, 2004). É preciso considerar, ainda, que as políticas de estado no Brasil não têm investido em ações institucionais permanentes que visem um acompanhamento permamente do licenciado ao longo de sua trajetória profissional (GARIGLIO et al., 2013). 
A trajetória profissional do professor compreende diferentes fases que vão desde a inicial até aquela que culmina com o fim da carreira docente. Considerando que o objeto de análise, desta investigação, privilegia a fase inicial, menciona-se Gonçalves (1995) que define o professor iniciante como aquele que se encontra entre o primeiro e o quarto anos de atuação. Já Huberman (1995) expõe que o professor está em início de carreira entre o primeiro e terceiro anos de exercício docente. Nessa fase, que marca o início da trajetória profissional, esse sujeito encontra-se em intenso processo de aprendizagem profissional e busca de identidade profissional (SANTOS, 2000; PIZZO, 2004).

Trata-se de um período em que ocorre a transição de estudante para professor e demanda do sujeito o desenvolvimento de habilidades e destrezas em um curto espaço de tempo (GARCIA, 1999; TARDIF, 2011).

Alguns pesquisadores entendem esse período como aquele em que o professor poderá se encontrar em "choque com a realidade" (HUBERMAN, 1995; GONÇALVES, 1995; SILVA, 1997; GUARNIERI, 2005, MIRANDA, 2010). Isso porque o início da carreira docente envolve uma série de experiências que podem resultar em construções positivas ou não acerca da profissão. Trata-se do primeiro contato, na condição de professor, com a realidade concreta e, portanto, demarca um momento ímpar na trajetória profissional que, por conseguinte, implicará na constituição dos referenciais de ação, crença, descobertas, intuição e conhecimento do professor (FERREIRA, 2006). Dentre os possíveis fatores que levam o professor iniciante a vivenciar o "choque com a realidade", encontra-se a formação inicial que não propiciou a este, enquanto aluno, grandiosas experiências práticas ou, ainda, uma realidade escolar dura demais, sem infraestrutura, socialização de informações e saberes entre professores (VEENMAN, 1984).

Outro aspecto que precisa ser considerado, no início da carreira docente, é a relação que esse sujeito irá estabelecer entre os conhecimentos teóricos e técnicos adquiridos no curso de formação inicial com as vivências práticas na ambiência da escola. Dito em outras palavras, trata-se da necessária articulação entre teoria e prática. Isso porque, apesar das discussões e propostas evidenciadas, ao longo das últimas décadas, nas pesquisas sobre formação de professores (SCHÖN, 1992; ZEICHNER, 1993; GIROUX, 1997;
FIORENTINI, 2003; PIMENTA, 2005) e reformas educacionais realizadas na década de 1990, tanto no Brasil como em vários países da América Latina (GENTILE, 1998), a realidade mostra que a dicotomia entre a teoria e prática, ainda se configura como uma situação a ser superada. Nessa direção, Borges (2005), afirma que nos cursos de formação inicial ainda se mantém uma separação entre teoria e prática, e não uma articulação, que se revela na organização curricular. Assim, segundo a autora, tanto a formação nos conteúdos como a formação pedagógica são realizadas separadas das vivências de situações enfrentadas pelos professores na sua prática cotidiana.

Para além da necessária articulação entre teoria e prática, é preciso considerar, nos cursos de formação inicial, uma justaposição entre os conhecimentos específicos com as relidades sociais em que se inserem as escolas (BEHETS; VERGAUWEN, 2006; NASCIMENTO et al., 2009; PIMENTA, 2002; REALI; NONO e MIZUKAMI, 2006; ZEICHNER, 2013). Pois, a não correspondência entre os conhecimentos teóricos e técnicos e o campo de atuação - nesse caso, a escola - em alguns casos, tem levado o professor, no início da carreira, a experimentar um sentimento de rejeição pela formação recebida. Sentimento esse que, em alguns casos, se traduz pela desqualificação que esses professores fazem aos seus cursos de formação inicial (TARDIF; RAYMOND, 2000).

Nessa perspectiva, as discussões que envolvem os contextos e cenários sociais em que decorrem a formação inicial em Educação Física sempre mereceram destaque e preocupação no âmbito acadêmico brasileiro. Essas discussões ganharam maiores proporções, especialmente nas duas últimas décadas, em função de eventos como: vigência da atual LDB (Lei 9.394/96); a instituição da Lei 9.696/98, que dispõe sobre a regulamentação da profissão em Educação Física; e a criação das Diretrizes Curriculares Nacionais para os cursos de Educação Física por meio da Resolução CNE/CES n. 7/2004, que foi precedida por polêmicas até a sua aprovação em 2004 (BRASIL, 1996; BRASIL, 1998; BRASIL, 2004). No epicentro desses debates e discussões, sempre estiveram presentes as especificidades existentes entre licenciatura e bacharelado, principalmente no que concerne às atribuições e competências específicas ligadas aos respectivos campos de intervenções.

Cumpre destacar que a formação inicial tem a função de propiciar ao futuro professor um conjunto de conhecimentos que lhe possibilite, 
quando no exercício da docência, reelaborar continuamente os saberes iniciais a partir do confronto com as expectativas vivenciadas no cotidiano escolar (LEONE; LEITE, 2011). Nessa direção, a formação inicial é concebida como a base para a aprendizagem continuada do professor ao longo de sua trajetória profissional.

Ao se considerar a formação inicial em Educação Física para as duas habilitações (licenciatura e bacharelado) e suas integralizações, o curso de licenciatura, por exemplo, tem, na matriz curricular, um número maior de disciplinas da chamada dimensão didática e pedagógica, e diminuição das disciplinas técnico instrumentais e biológicas (SILVA, 2011). O autor acrescenta, ainda, que essa situação se encontra de maneira inversa na matriz curricular do curso de bacharelado. Assim, em decorrência do entendimento e, por conseguinte, das adequações que são realizadas nas matrizes curriculares dos cursos de licenciatura e bacharelado pelas instituições de ensino superior no Brasil, tem-se, por vezes, descaracterizada a formação inicial que seja capaz de subsidiar o professor de saberes específicos e necessários numa proporcionalidade que permita uma atuação plena na educação básica (licenciatura). Em outras palavras, nem sempre a formação inicial prepara o futuro professor para atuar na licenciatura mas, volta-se à prepará-lo, quase exclusivamente, para trabalhar com os esportes e com o treinamento desportivo (MIRANDA, 2010). Isso porque, ainda que licenciatura e bacharelado em Educação Física se configurem como campos distintos de intervenção, percebe-se, na maioria dos cursos de formação, uma matriz curricular muito próxima, variando poucas disciplinas entre as duas habilitações, o que poderia levar a crer em mesmo perfil profissional, mesmas competências e um mesmo tipo de intervenção (SILVA, 2011).

Essas considerações evidenciam que, apesar da existência das Diretrizes Curriculares Nacionais, muitas instituições de ensino superior no país ainda têm mostrado dificuldades em estabelecer perfis profissionais distintos para o licenciado e para o bacharel em Educação Física.

Tendo em vista que a formação inicial nem sempre propicia uma total apreensão por parte do professor de saberes específicos e necessários à sua atuação profissional, faz-se relevante analisar o processo de aprendizagem profissional do licenciado em Educação Física em início da carreira no excercício do magistério. Nessa perspectiva, o objetivo deste estudo, foi analisar as dificuldades encontradas pelo professor de Educação Física no início de carreira docente, atuante em escolas de educação básica na cidade de Ouro Preto, MG.

\section{Metodologia}

Considerando o fenômeno estudado, a trilha científica das ciências humanas e sociais se mostrou a mais indicada para nortear a averiguação dos objetivos estabelecidos. Este estudo se caracteriza como uma pesquisa de natureza qualitativa na qual, de acordo com Minayo (2011), trabalha-se com um universo de significados, motivos, aspirações, crenças, valores e atitudes. Isso corresponde a um espaço mais profundo das relações, dos processos e dos fenômenos, que não podem ser reduzidos à operacionalização de variáveis. Como instrumento de coleta de dados, foi empregada a entrevista semiestruturada elaborada a partir da literatura especializada e conduzida e fundamentada em estudos de Spradley (1979) que assinala a entrevista como sendo um evento discursivo, o qual, por sua vez, pode ser descrito pelo modo de conduzir alguns diálogos em ocasiões ou encontros sociais. Nesta perspectiva, o autor entende as entrevistas como uma série de conversações entre amigos, dentro das quais o pesquisador suavemente introduz novos elementos para ajudar os informantes a responder como informantes.

Dentre os procedimentos adotadas na definição do grupo amostral, foram estabelecidos contatos com a Superintendência Reginal de Ensino da cidade de Ouro Preto, que forneceu a relação de todas as escolas de educação básica localizadas na cidade de Ouro Preto. Dessa forma, por meio de contatos telefônicos com as secretarias das respectivas escolas foi feito um levantamento de informações sobre os professores de Educação Física que se encontravam vinculados às mesmas. $\mathrm{Na}$ impossibilidade de algumas secretarias fornecerem informações precisas acerca do tempo de formação do professor, eram agendadas novas chamadas para que as informações pudessem ser confirmadas nas documentações existentes nas escolas e, em alguns casos, diretamente com o professor. Após o levantamento inicial, foram contabilizados 11 professores que se encontravam na fase denominada por Huberman (2007) como inicio de carreira docente. $\mathrm{Na}$ sequência, foram realizadas visitas nas escolas onde os professores se encontravam atuantes para apresentação do estudo e confirmação sobre a participação ou não dos 
mesmos como sujeitos da pesquisa. Em decorrência da impossibilidade de agendamento de horários e mesmo da recusa em participar da pesquisa, a amostra final constituiu-se por oito professores licenciados em Educação Física que se encontravam no início de carreira docente. A formação inicial dos sujeitos se deu em instituições de ensino superior públicas e privadas, e atuavam em escolas da rede pública municipal, estadual e privada de ensino básico localizadas na cidade de Ouro Preto, MG. Antes da realização da entrevista, os sujeitos foram informados dos aspectos relativos à pesquisa, receberam um Termo de Consentimento Livre e Esclarecido (TCLE) contendo informações sobre a pesquisa, que foi lido e assinado por eles. Como critérios de inclusão foram considerados: professores licenciados em Educação Física com até três anos de prática profissional - fase denominada por Huberman (2007) como início de carreira e, após tomarem ciência dos objetivos e natureza da pesquisa, a assinatura do TCLE. Consideraram-se como critérios de exclusão os professores que se encontram atuando há mais de três anos, sujeitos sem formação em licenciatura em Educação Física, a recusa da assinatura do TCLE e o não interesse em participar da investigação.

A coleta de dados ocorreu, de outubro a dezembro de 2014, nas escolas em que os professores atuavam, mediante contatos prévios e agendamentos com os mesmos, conforme ressaltado.

$\mathrm{Na}$ análise dos dados, foi utilizada a técnica de análise de conteúdo que, de acordo com Bardin (2011), refere-se a um conjunto de técnicas de análise das comunicações visando obter, por procedimentos sistemáticos e objetivos de descrição do conteúdo das mensagens, indicadores quantitativos ou não que permitem a inferência de conhecimentos relativos às condições de produção/recepção (variáveis inferidas) destas mensagens. A autora organiza a análise de conteúdo a partir das fases: pré-análise, exploração do material e tratamento dos resultados, inferência e interpretação. Em consonância com essas fases, após transcrição e análise interpretativa dos dados coletados, estes foram organizados - por meio de agrupamentos em categorias de análise constituídas por elementos comuns presentes nesses dados - e posteriormente quantificados a partir da frequência de ocorrência em que essas categorias se faziam presentes. Concluída a etapa de análise de conteúdo, para fins de apresentação, os dados foram reagrupados em três segmentos dispostos em duas tabelas e um quadro. Na sequência em que os resultados se encontram dispostos no presente artigo, na Tabela 1 encontram-se reunidos os dados sobre a formação inicial em Educação Física e os conhecimentos específicos para atuação na educação básica, no quadro 1 os dados referentes à dificuldades vivenciadas nas práticas de intervenção na educação básica e, finalmente na Tabela 2 os dados relativos às formas de aquisição dos conhecimentos específicos para a atuação docente. A discussão desenvolveu-se através da triangulação entre os dados das entrevistas realizadas com os professores participantes da pesquisa, a bibliografia utilizada especializada no tema em questão e, também, as posições assumidas pelos autores da investigação em relação ao fenômeno analisado.

A pesquisa obteve aprovação junto ao Comitê de Ética em Pesquisa da Universidade Federal de Ouro Preto, ofício CEP Nº. 006/2012, de 1 de fevereiro de 2013.

\section{Resultados e discussão}

De acordo com os dados levantados, a categoria de professores no início de carreira, atuantes em escolas de ensino básico na cidade de Ouro Preto, MG, com tempo de docência na educação básica em torno de 1,7 anos, com desviopadrão de 1,23 . A maioria dos participantes $(62,5 \%)$ se formou em instituições de ensino superior públicas federais e os demais $(37,5 \%) \mathrm{em}$ instituições privadas.

Ainda que se tratem de professores com formação em licenciatura, chama a atenção, o fato de esses sujeitos não atuarem de forma exclusiva na escola. De acordo com os depoimentos obtidos, esses professores desempenham atividades profissionais, de forma paralela, que não correspondem à licenciatura e sim ao bacharelado em Educação Física. Dentre essas atividades, destacam-se treinamento de atletas em clubes, atuação como instrutor de academias de ginástica e, ainda, em estúdios de pilates. Em estudo realizado por Paixão et al. (2014), foi analisada a atuação de licenciados em Educação Física em academias de ginástica, bem como a aquisição de saberes e competências necessárias a uma área de intervenção a qual esses sujeitos não detinham formação inicial. Os resultados mostraram que, dentre os fatores que concorrem para a manutenção desta situação, sobressaem aqueles relacionados à forma como se dá a escolha pelo curso de Educação Física. Isso porque o candidato concebe a Educação Física 
como um campo de intervenção profissional que se restringe à ambiência do bacharelado. Em outras palavras, uma área de atuação que se efetiva em academias de ginástica e atividades de personal trainner. De acordo com os professores licenciados, enquanto o bacharelado tem o potencial de lhes proporcionar status social, visibilidade, a escola, por sua vez, se apresenta como um campo de batalhas no qual se veem diante de problemas constantes como indisciplina, precariedade de recursos materiais e espaços para as aulas, bem como a remuneração salarial pelos serviços ali prestados. Não obstante a isso, o estudo de Paixão et al. (2014) ainda revela que a forma como as matrizes curriculares dos cursos são organizadas compromete a construção de uma entidade, de bacharelado ou licenciatura, pelo acadêmico. Esse fato propicia uma falsa ideia de abrangência ilimitada de atuação profissional para áreas em que não se teve uma formação inicial específica.

No que se refere à formação inicial, buscouse averiguar se o curso de licenciatura em Educação Física possibilitou aos professores os conhecimentos específicos e necessários para sua atuação na educação básica como mostra a Tabela 1.

Tabela 1 - Formação inicial em Educação Física e os conhecimentos específicos para atuação na educação básica

\begin{tabular}{lc}
\hline & \multicolumn{1}{c}{$\begin{array}{c}\text { Licenciados em } \\
\text { A FORMAÇÃO INICIAL EM EDUCAÇÃo FÍSICA ... }\end{array}$} \\
\cline { 2 - 2 } $\begin{array}{l}\text { não possibilitou conheca } \\
\text { a prática de intervenção pedagógica }\end{array}$ & 56,7 \\
$\begin{array}{l}\text { possibilitou conhecimentos específicos (predominantemente teórico) } \\
\text { relacionados a prática de intervenção pedagógica }\end{array}$ & 18,3 \\
$\begin{array}{l}\text { possibilitou conhecimentos específicos (teórico-prático) } \\
\text { prática de intervenção pedagógica }\end{array}$ & \\
\begin{tabular}{l} 
TOTAL \\
\hline
\end{tabular} & $\mathbf{1 0 0}$ \\
\hline
\end{tabular}

Fonte: Autores

A Tabela 1 mostra que $75 \%$ dos professores participantes desta pesquisa relataram que a formação inicial não lhes proporcionou conhecimentos específicos numa proporção equânime e relacional entre teoria e prática para atuarem como professores na educação básica. Ressaltou-se, nas falas desses professores, o fato de não se sentirem preparados para lidarem com as diferentes demandas inerentes à ação docente na escola como, por exemplo, o trato didático pedagógico com os conteúdos da Educação Física, tendo em vista a faixa etária dos alunos, bem como na realização de atividades como planejamento e elaboração de aulas. Esse dado sinaliza elementos para se pensar sobre a prevalência do modelo da racionalidade técnica que, durante muito tempo, balizou a organização dos currículos de formação de professores. Modelo esse que implica diretamente na dissociação teoria e prática.

Em que pese a dificuldade por parte dos professores em início de carreira, em aplicar o conhecimento teórico na prática do dia-a-dia, haja vista a complexidade e ao caráter imprevisível das situações que se apresentam na ação docente, em tese, o estágio curricular configura-se momento de excelência no decorrer da formação inicial, no qual o acadêmico poder-se-ia concretizar importantes momentos vivenciais. No entanto, a forma como, geralmente, são estruturados os estágios supervisionados nos cursos de formação inicial somatiza inúmeras fragilidades, não garantindo aos futuros professores uma preparação que os capacite para plena intervenção no ambiente de trabalho (PIMENTA; LIMA, 2012). Essa situação, que coloca em questionamento a eficácia dos estágios supervisionados nos cursos de formação inicial no Brasil, foi apontada por Menga Lüdke ainda no final da década de 1980. A autora denunciou como individualista o caráter da relação que se estabelece entre o aluno estagiário e o profissional que assume o papel de supervisor de campo. Isso porque, o estagiário recebe muito pouca ajuda e orientação do 
supervisor, inexistindo uma relação que possa assegurar o treinamento e a prática do futuro professor (LÜDKE, 2011).

Tal situação leva à conclusão que há distanciamento entre as normatizações de princípios e procedimentos oficiais a serem adotados pelas instituições formadoras de ensino superior no país e a sua efetivação nos cursos de formação inicial. Como exemplo, para a formação inicial em Educação Física, as Diretrizes Curriculares Nacionais (Res. n. 07/04) orientam as instituições de ensino superior para a construção de uma formação específica, privilegiando as competências intelectuais que atendam às demandas sociais na área de intervenção (BRASIL, 2004).

Compete ressaltar aqui que, ainda que a formação do professor seja entendida sobre uma ótica atemporal, que se inicia com a formação inicial e se estende no decorrer de sua trajetória profissional (PIMENTA, 2012), cabe às agências formadoras a responsabilidade pela formação inicial dos sujeitos, com vistas à aquisição de competências profissionais, atentando-se, sobretudo, às mudanças e tendências de um dado campo de intervenção social (MASSA, 2002). No caso dos cursos de bacharelado em Educação Física, os projetos pedagógicos, nas instituições de ensino superior, devem, sobretudo, articular as unidades de conhecimento na perspectiva da formação ampliada e específica (NUNES; VOTRE; SANTOS, 2012).

Uma questão polêmica que parece prevalecer nas discussões acerca da estruturação curricular dos cursos em Educação Física envolve o núcleo básico de conhecimentos. Alguns advogam pelos conhecimentos eminentemente profissionalizantes de cunho aplicado. Já outros têm se colocado no extremo oposto, defendendo conhecimentos essencialmente acadêmicos e básicos. De acordo com Tani (2007), ambos os conhecimentos se mostram importantes, e devem ser trabalhados de forma equânime com vistas à uma formação sólida de conhecimentos acadêmicos amplos e gerais sobre o objeto de estudo movimento humano ou cultura do movimento adquiridos de forma integrada e não fragmentada.

Os depoimentos dos professores também revelaram diferentes dificuldades vivenciadas em sua prática de intervenção cotidiana na escola, na fase considerada início de carreira, como apresentado no Quadro 1.

Quadro 1 - Dificuldades vivenciadas nas práticas de intervenção na educação básica

\section{DIFICULDADES}

Falta de reconhecimento e valorização da Educação Física como componente curricular por parte da comunidade escolar

Dificuldade no relacionamento com os alunos devido a indisciplina e aceitação de novas metodologias no trato com os conteúdos da Educação Física Distanciamento entre a universidade e a escola em termos de realidades percebidas

Insegurança por assumir o protagonismo das turmas como professor(a)

Precariedade da infraestrutura e materiais pedagógicos para as aulas

Fonte: Autores

Diante do Quadro 1, são pertinentes algumas considerações. Na escola, a Educação Física se configura de maneira diferenciada, haja vista sua especificidade como área do saber que tem como objeto de estudo o movimento humano mediatizado pelas diferentes práticas corporais e culturais e, com isso, a alegria, a descontração e, acima de tudo, o prazer vivenciado por uma parcela significativa de alunos no seu decurso. Como contra ponto, por vezes, essa mesma especificidade leva a interpretações equivocadas sobre a Educação Física, tanto por parte dos alunos quanto pelos próprios professores com formação na referida área, chegando, em alguns casos, a ser percebida exclusivamente como atividade prática com ênfase no aspecto técnico e tático de modalidades esportivas (DARIDO; RANGEL, 2005). Soma-se a isso, a falta de incentivos para o trabalho na escola, com a inexistência de estrutura física e materiais pedagógicos adequados e, em alguns casos, a não legitimidade junto à própria comunidade escolar (VAGO, 1996). Em pesquisa realizada sobre a inserção do professor iniciante de Educação Física na escola, Gori (2000) afirma que a estrutura e organização da escola, as condições físicas e materiais por ela oferecidas acabam interferindo 
sobremaneira no processo de inserção profissional, comprometendo o desenvolvimento da prática docente, na medida em que as atividades propostas nas aulas restringem-se àquelas que se utilizam apenas do material disponível. $\mathrm{Na}$ mesma proporção, o espaço físico constitui-se num fator limitador de algumas práticas corporais propostas pela disciplina, quando não oferece as condições necessárias para as aulas e exige do professor uma improvisação permanente.

Ao se analisar aspectos que permeiam a Educação Física e a efetivação de sua prática pedagógica nos segmentos que compõem a Educação Básica (NEIRA; NUNES, 2009; KUNZ; TREBELS, 2006), é possível afirmar que se vive um momento em que se converteu em lugar-comum a insatisfação, por parte dos professores, em relação às condições de trabalho encontradas nas instituições de ensino público. Dentre as principais queixas dos professores, encontram-se a falta de espaços físicos e materiais pedagógicos destinados às aulas práticas, o não engajamento dos pais na vida escolar dos filhos, o que, por sua vez, repercute diretamente no alarmante índice de indisciplina e desinteresse por parte dos alunos.

Os primeiros contatos na condição de professor com a realidade concreta na escola, constitui uma fase em que incertezas e choques com a realidade são inevitáveis (HUBERMAN, 2007). Nela, o professor iniciante encontra-se suscetível a uma série de experiências que podem resultar em construções positivas ou não acerca da profissão. Contudo, trata-se de um momento ímpar na trajetória profissional que, por conseguinte, implicará na constituição dos referenciais de ação, crença, intuição e conhecimentos do docente (FERREIRA, 2006). Nessa direção, percebe-se que os depoimentos dos professores participantes desse estudo coadunam com estudos na área de formação de professores (HUBERMAN, 1995; GONÇALVES, 1995; GUARNIERI, 2005), que afirmam sobre necessidade de aproximação entre formação acadêmica e realidade escolar. Dentre os caminhos para se amenizar a situação, chega a ser unânime a urgência de reestruturação e adequação das propostas curriculares dos cursos que formam os professores que os permitam compreender o trabalho pedagógico e intervir no cotidiano da escola (BORGES, 1998). Ao analisarem sob a ótica dos professores, Tardif e Raymond (2000) concluíram que os saberes teóricos (científicos e pedagógicos) obtidos nas universidades não mantêm uma correspondência completa e satisfatória com os saberes da prática (experienciais).

Apesar da relevância da formação inicial no processo de profissionalização, o diploma não se configura sinônimo de competência e garantia de qualidade nas práticas de intervenção. Estudos sobre a formação inicial de professores compartilham da premissa de que o aprendizado do trabalho docente não se restringe à formação acadêmico-profissional (GUARNIERI, 2005; TARDIF, 2011; PIMENTA, 2012). Os referidos autores completam que as experiências diretas com o fazer do próprio trabalho são fundamentais, pois é, nesta instância, que serão aprendidos, produzidos e articulados aos saberes práticos outros saberes abordados ao longo da formação inicial como os saberes de natureza científica e pedagógica. Por assim, dizer, infere-se que o processo de formação docente resulta da articulação de diferentes tipos de saberes a serem vivenciados pelo sujeito ao longo de sua trajetória profissional (TARDIF, 2011; PIMENTA, 2012). A formação inicial não somente fornece as bases de conhecimentos numa determinada área de intervenção profissional, como ainda proporciona informações de como acessar outros conhecimentos e informações correlatas que se fazem necessárias com as demandas que um determinado contexto social ou ambiência de atuação possam requerer. De acordo com Francisco e Pereira (2004), o estágio constitui uma etapa fundamental na formação do aluno, tendo este o contato com a realidade do seu campo de atuação. Este é um momento da formação em que o graduando pode ter diferentes aprendizados, conhecendo melhor sua área de atuação. O estágio ainda é percebido por Roerch (1999), como a chance que $o$ acadêmico tem para aprofundar conhecimentos e habilidades nas áreas de interesse do aluno. É também, nessa oportunidade, que o acadêmico vê realmente a realidade cotidiana e a complexidade da sua futura profissão. Tendo em vista a situação encontrada na realidade concreta, somado ao que apontam estudos como o realizado por Pimenta e Lima (2012), se faz necessário e urgente um repensar na forma como os estágios curriculares se estruturam nos cursos de formação inicial em muitas instituições de ensino superior no País.

Como mostra a Tabela 2, os entrevistados têm diferentes formas de aquisição dos conhecimentos específicos para atuação docente. 
Tabela 2 - Formas de aquisição dos conhecimentos específicos para a atuação docente

\begin{tabular}{lc}
\hline \multirow{2}{*}{ CATEGORIAS } & $\begin{array}{c}\text { Licenciados em } \\
\text { Educação Física }\end{array}$ \\
\cline { 2 - 2 } & $\%$ \\
\hline Referencial teórico (livros, artigos e demais publicações na área) & 44,9 \\
Sites com informações específicas dos conteúdos trabalhados nas aulas & 39,8 \\
Troca de informaçóes com professores mais tempo de docência na área & 9,7 \\
Outras fontes & 5,6 \\
TOTAL & 100 \\
\hline
\end{tabular}

Fonte: Autores

Com base nos dados da Tabela 2, oberva-se que, dentre as formas de aquisição dos conhecimentos que relacionam-se diretamente à sua atuação na educação básica, as categorias mais expressivas foram o contato com referencias teóricos específicos na área $(44,9 \%)$ e a busca por informações em sites da internet $(39,8 \%)$. Esses dados revelam, de forma inequívoca, a iniciativa, por parte dos licenciados em Educação Física no início de carreira, na aquisição de conhecimentos específicos básicos da docência em Educação Física. Sobre essa questão, Gori (2000), afirma que a forma como as disciplinas desportivas foram ministradas no curso de formação inicial não preparou o futuro professor para o contexto escolar. Em outras palavras, a prática ficou prejudicada devido ao fato de o ensino da técnica não ter sido privilegiado. Dentre as implicações dessa situação se tem a busca incansável pelo conhecimento técnico-prático, citados pelos sujeitos da pesquisa como alternativas para contornar um problema que se relaciona diretamente à inconsistência de conhecimentos e habilidades básicas para o desempenho da função docente.

Ao prosseguir na discussão dos dados apresentados (Tabela 2) evidencia-se uma situação real que envolve sujeitos que passaram por um curso de licenciatura em Educação Física. Significa afirmar que se tratam de professores que, em tese, deveriam possuir os conhecimentos acadêmicos e pedagógicos específicos e necessários à referida área de atuação na escola. Com isso, não se pode negar que se trata de uma situação inadequada e alarmante no âmbito da formação de professores. No entanto, ainda que essa iniciativa por parte dos professores em inicio de carreira não se traduza no ideal, mas em sinal de fragilidade na formação inicial, não se pode invalidar de forma categórica a sua contribuição no processo de edificação dos saberes relacionados à prática profissional docente. Nessa direção, espera-se desses sujeitos o discernimento sobre as informações obtidas no que se refere a sua adequação aos alunos, suas realidades e necessidades num dado tempo e espaço no âmbito escolar. Por fim, o compartilhamento de ideias, do fazer pedagógico, dos conhecimentos muito próprios da docência em Educação Física, troca de informações com professores com maior tempo de experiência na docência revela-se com o percentual de $9,7 \%$ dos participantes desta investigação. Como afirma Fontana (2010), trata-se de um recurso comumente observado entre os professores no início de carreira ao chegar à escola. Em contra partida, Behrens (1996) observa que não é através de receitas e prescrição de modelos metodológicos buscados pelos professores iniciantes com colegas mais experientes na escola que garantirá uma nova postura pedagógica do mesmo.

Ressalta-se que, dentre as formas de aquisição de conhecimentos específicos relacionados à atuação docente apontadas pelos professores no início de carreira, não foram relatadas participação em congressos, simpósios, cursos de curta duração, pós-graduação lato ou strictu sensu. A preocupação percebida, nesses dados, se deve ao fato de se tratar de formas de atualização profissional que convencionou denominar na área da educação de formação docente continuada (PRADA; FREITAS; FREITAS, 2010).

\section{Considerações Finais}

Diante das constatações obtidas, nesta investigação, e considerando suas limitações metodológicas, é possível afirmar que, ainda que se tenha considerado como sujeitos do estudo professores licenciados em Educação Física, uma parcela considerável envereda-se profissionalmente em áreas de atuação que se destinam ao bacharel e, por vezes, em áreas que distam completamente da Educação Física. Esta situação suscita antigas 
discussões, que parecem prevalecer entre licenciatura e bacharelado, principalmente no que concerne às atribuições e competências específicas ligadas aos respectivos campos de intervenções. Ainda que se tratem de campos distintos de intervenção, percebe-se, na maioria dos cursos de formação, uma matriz curricular muito próxima, variando poucas disciplinas entre as duas habilitações, o que poderia levar a crer em mesmo perfil profissional, mesmas competências e um mesmo tipo de intervenção (SILVA, 2011). Esses dados mostram a dificuldade por parte das instituições de ensino em definir os objetivos e perfis profissionais do seu curso, que assim realmente diferenciem a licenciatura do bacharelado.

Não obstante a isso, a alteração nas Diretrizes Curriculares Nacionais para a formação de professores da educação básica no que se refere à carga horária mínima que passou de 2.800 para 3.200 horas (Parecer CNE/CP N. 2/2015) abre novas possibilidades para se repensar e buscar novas alternativas para a referida discrepância entre licenciatura e bacharelado em Educação Física.

No que se refere à formação inicial, os resultados evidenciam que os conhecimentos adquiridos durante o curso de licenciatura em Educação Física se mostraram insuficientes para a sua atuação plena, principalmente no que se diz respeito à relação entre conhecimentos específicos teóricos e práticos. Outras dificuldades apontadas pelos professores em início de carreira se referem ao choque de realidade envolvendo a escola, os alunos, a forma como a Educação Física é concebida entre a comunidade escolar.

A aquisição dos conhecimentos específicos para a atuação docente ocorre de diferentes formas como a busca em referenciais teóricos contidos em livros, artigos e em sites relacionados à área, o contato direto com professores experientes na escola e em eventos na área.

Não foi evidenciado, nos depoimentos dos entrevistados, o desejo e a percepção de necessidade de se ingressar em cursos de formação continuada como especialização, mestrado e doutorado na área da licenciatura em Educação Física. Esse dado, somado à fragilidade da formação inicial em proporcionar os saberes específicos e necessários para a docência, se mostra muito preocupante.

Tendo em vista os dados obtidos nesta investigação, corre-se o risco de se ter uma atuação docente que dista de ser uma atuação reflexiva e consistente, convertendo-se em um ativismo acrítico e, a partir desse momento, os anos passam, mas a experiência acumulada poderá apenas servir para autojustificar suas próprias ações e desenvolver uma atitude defensiva frente à atuação profissional em uma área para qual não se tenha formado.

A busca por parte das instituições formadoras em implementar cada vez mais as experiências vivenciadas pelos acadêmicos na formação inicial de professores em Educação Física para atuar na educação básica é um esforço que merece ser concretizado. Desta forma, sugerem-se novas investigações sobre o tema, incluindo observação do espaço de intervenção e análise aprofundada de outros elementos presentes nas matrizes curriculares dos cursos de formação incial no País.

\section{Nota}

$1 \mathrm{O}$ projeto de pesquisa teve como órgão financiador a Fundação de Amparo à Pesquisa do Estado de Minas Gerais - FAPEMIG no período de março de 2014 a fevereiro de 2015.

\section{Referências}

BARDIN, L. Análise de conteúdo. Trad. Luís Antero Reto e Augusto Pinheiro. 4a ${ }^{\mathrm{a}}$ ed. Lisboa: Edições 70, 2011.

BEHETS, D.; VERGAUWEN, L. Learning to teach in the field. In: KIRK, D.; MacDONALD, D.; O' SULLIVAN, M. (Org.). Handbook of physical education. London: Sage, 2006. p.407-424.

BEHRENS, M. A. A prática pedagógica dos professores universitários: perspectivas e desafios. In: IXX Reunião Anual ANPED, Caxambu, MG, set.1996.

BORGES, C. A formação dos docentes de educação física. In: BORGES, C.; DESBIENS, J. F. (Orgs.). Saber, formar e intervir para uma educação física em mudança. Campinas: Autores Associados, 2005. BRASIL. Conselho Federal de Educação. Resolução n. 3, de 16 de junho de 1987. Diário Oficial n.172, Brasília, 1987.

. Conselho Nacional de Saúde. Resolução número 466, de 12 de dezembro de 2012. Brasília, 2012. Disponível em: 
<http://www.conselho.saude.gov.br/web_comissoes /conep/index.html>. Acesso em: 04 fev. 2014.

Ministério da Educação/Conselho Nacional de Educação/Câmara de Educação Superior. Resolução ${ }^{\circ}$ 7, de 31 de março de 2004. Diretrizes Curriculares Nacionais para os cursos de graduação em Educação Física. Brasília: MEC, 2004b. Disponível em: http://portal.mec.gov.br/c ne/arquivos/pdf/ces0704edfisica.pdf. Acesso em: 07 ago. 2014.

DARIDO, S. C.; RANGEL, I. C. A. Educação Física na Escola: implicações para a prática pedagógica. Rio de Janeiro: Guanabara Koogan, 2005.

FERREIRA, L. A. O professor de Educação Física no primeiro ano da carreira: análise da aprendizagem profissional a partir da promoção de um programa de iniciação a docência. 2006, 229p. Tese (Doutorado em Educação). Programa de PósGraduação em Educação. São Carlos: UFSCar, 2006.

FIORENTINI, D.; SOUSA JR., A. J.; MELO, A. G. F. Saberes docentes: um desafio para acadêmicos e práticos. In: GERALDI, C. M. G.; FIORENTINI, D.; PEREIRA, E. M. de A. (Orgs.). Cartografia do trabalho docente: professor(a) pesquisador(a). $3^{\mathrm{a}} \mathrm{ed}$. Campinas (SP): Mercado de Letras, 2003, p.307335.

FONTANA, R. A . C. Como nos tornamos professoras?. $3^{\text {a }}$ ed. Belo Horizonte: Autêntica, 2010.

FRANCISCO, C. M.; PEREIRA, A. S. Supervisão e sucesso do desempenho do aluno no estágio, 2004. Revista Digital. Buenos Aires - Año 10 - № 69 Febrero de 2004. Disponivel em: $<$ http://www.efdeportes.com/>. Acesso em: 16-072015.

GARCIA, M. C. Formação de professores: para uma mudança educativa, Porto, Portugal: Editora Porto, 1999.

GARIGLIO, J.A. et al. Projeto de formação continuada de professores iniciantes de educação física. XVIII Congresso Brasileiro de ciência do desporte, V Congresso Internacional de Ciência do desporte, tema Identidade da Educação Física e ciência do desporto em tempos de megaeventos. Brasília, DF, 2013.

GENTILE, P. Pedagogia da exclusão: crítica ao neoliberalismo em educação. Petrópolis: Vozes, 1998.

GIROUX, H. Os professores como intelectuais: rumo a uma pedagogia crítica da aprendizagem. trad. Daniel Bueno. Porto Alegre: Artes médicas, 1997.

GONÇALVES, J. A. M. A carreira das professoras do ensino primário. In: NÓVOA, Antônio (org.) Vida de professores. Portugal: Porto Editora, 1995, p.141- 169.

GORI, R. M. A. A inserção do professor iniciante de educação física na escola. 2000, 114p. Dissertação (Mestrado em Educação). Programa de Pós-Graduação em Educação da Universidade de Minas Gerais. Faculdade de Educação da UFMG, 2000.

GUARNIERI, M. R. Aprendendo a ensinar: o caminho nada suave da docência. $2^{\text {a }}$ ed. São Paulo: Autores Associados, 2005.

HUBERMAN, M. Ciclo de vida profissional dos professores. In: NÓVOA, A. (org.) Vida de professores. Porto/Portugal: Porto Editora, 2007, p.31-61.

KUNZ, E.; TREBELS, A. H. Educação Física crítico-emancipatória: com uma perspectiva da pedagogia alemã do esporte. Ijuí: Unijuí, 2006.

LEONE, N. M.; LEITE, Y. U. F. O início da carreira docente: implicações à formação inicial de professores. Revista Eletrônica Pesquiseduca, Santos, v. 3, n. 6, p. 236-259, jul./dez. 2011.

LÜDKE, M; BOING, L. A. . Caminhos da profissão e da profissionalidade docentes. Revista Educação e Sociedade, Campinas, v. 25, n. 1, p. 1159-1180, set./dez. 2004.

MASSA, M. Caracterização acadêmica e profissional da Educação Física. Revista Mackenzie de Educação Física e Esporte, São Paulo, v. 1, n. 1, 2002. 
MINAYO, M. C. S. (org.) Pesquisa Social: teoria, método e criatividade. $30^{\mathrm{a}}$ ed. Petrópolis: Vozes, 2011.

MIRANDA, S. O desenvolvimento dos professores universitários de Educação Física e os ciclos de vida profissional: três estudos de caso. 2010. 459f. Dissertação (Doutorado em estudos da criança especialidade em educação física, lazer e recreação). Universidade do Minho, Instituto de Educação, Braga, Portugal, 2010.

NASCIMENTO, J.V. et al. Formação acadêmica e intervenção pedagógica nos esportes. Motriz: Revista da Educação Física, Rio Claro, v.15, n.2, p.358-66, 2009. Disponível em: <http://www.periodicos.rc.biblioteca.unesp.br/index .php/motriz/article/view/2251/2378>. Acesso em: 10 jul. 2014.

NEIRA, M. G.; NUNES, M. L. F. Educação física, currículo e cultura. São Paulo: Phorte, 2009.

NONO, M.A.; MIZUKAMI, M.G.N. Processos de formação de professoras iniciantes. Revista Brasileira de Estudos Pedagógicos, Brasília, v. 87, n. 217, p.382-400, 2006.

NUNES, M. P.; VOTRE, S. J.; SANTOS, W. O profissional em Educação Física no Brasil: desafios e perspectivas no mundo do trabalho. Motriz, Rio Claro, SP, v. 18, n. 2, p. 280-90, 2012.

PAIXÃO, J. A.; CUSTÓDIO, G. C. C.; BARROSO, Y. W. S.; Atuação de licenciados em Educação Física nas academias de ginástica: uma análise a partir dos saberes docentes. Pensar $a$ Prática, v. 17, n. 3, set. 2014. Disponível em: <http://www.revistas.ufg.br/index.php/fef/article/vi ew/29598/17106>. Acesso em: 14 Jul. 2015.

PIMENTA, S. G. Saberes pedagógicos e atividade docente. $8^{\mathrm{a}}$ ed. São Paulo: Cortez, 2012.

- O estágio na formação de professores. 5. ed. São Paulo: Cortez, 2002.

.; GHEDIN, E. Professor reflexivo no Brasil: gênese e crítica de um conceito. 3. ed. São Paulo: Cortez, 2005.

; LIMA, M. S. L. Estágio $e$ docência. $7^{\mathrm{a}}$ ed. São Paulo: Cortez, 2012.

PIZZO, S. V. O início da docência e a trajetoria profissional sengundo a visão de professores em final de carreira. 2004. 104f. Dissertaçao (Mestrado em Educação) Universidade Federal de São CarlosSão Carlos, 2004

PRADA, L. E. A.; FREITAS, T. C.; FREITAS, C. A. Formação continuada de professores: alguns conceitos, interesses, necessidades e propostas. Revista Diálogo Educacional, Paraná, v. 10, n. 30, 2010.

REALI, A.M.; MIZUKAMI, M.G. Práticas profi ssionais, formação inicial e diversidade: análise de uma proposta de ensino e aprendizagem. In: MIZUKAMI, M.G.; REALI, A.M. (Orgs.). Aprendizagem profissional da docência: saberes, contextos e práticas. São Carlos: EdUFSCar, 2002. p.119-38.

ROERCH, S. M. A, et al. Projetos de estágio e de pesquisa em administração: guia para estágios, trabalhos de conclusão, dissertações e estudos de caso. $2^{a}$ ed. São Paulo: Atlas, 1999.

SANTOS, H. F. H. Dificuldades de inserção profissional dos professores em início de Carreira. 2000.126f. Dissertação (Especialização em Educação de Infancia). Instituto Politécnico de Lisboa Escola Superior de Educação, Lisboa, 2000.

SCHÖN, D. Formar professores como profissionais reflexivos. In: NÓVOA, A. Os professores sua formação. Lisboa: D. Quixote, 1992. p. 81-91.

SILVA, M. C. O primeiro ano de docência: o choque com a realidade. In M. T. Estrela (Ed), Viver e construir a profissão docente. (p. 51-80). Editora Porto,1997.

SILVA, O. O. N. Licenciatura e Bacharelado em Educação Física: diferenças e semelhanças. Revista Espaço Acadêmico, Maringá, v.1, n. 124, p. 76-84, set. 2011.

SILVA, O. O. N. Licenciatura e Bacharelado em Educação Física: diferenças e semelhanças. Revista Espaço Acadêmico, Maringá, v.1, n. 124, p. 76-84, set. 2011. 
SPRADLEY, J. P. The ethnographic interview. Florida: Harcourt Brace Jovanovich, 1979.

TANI, G. Avaliação das condições do ensino de graduação em educação física: garantia de uma formação de qualidade. Revista Mackenzie de Educação Física e Esporte, São Paulo, v. 6, n. 2, 2007.

TARDIF, M. Saberes docentes e formação profissional. $16^{\text {a }}$ ed. Petrópolis: Vozes, 2011.

TARDIF, M.; RAYMOND, D. Saberes, tempo e aprendizagem do trabalho no magistério. Revista Educação e Sociedade, Campinas, v. 21, n. 73, p. 209-244, dez. 2000.

\section{Sobre os autores}

Jairo Antônio da Paixão: Professor Adjunto da Universidade Federal de Viçosa (UFV). Coordenador do Laboratório de Estudos Pedagógicos em Educação Física (LEPEF). Docente do Programa de Pós-Graduação em Educação do Instituto de Ciências Humanas e Sociais da Universidade Federal de Ouro Preto, MG.

Yuri Windson Santos Barroso: Acadêmico do Curso de Bacharelado em Educação Física da Universidade Federal de Ouro Preto, MG. Bolsista de iniciação científica do Projeto de Iniciação a Pesquisa da Universidade Federal de Ouro Preto, MG - PIP/UFOP e Coordenador de Minas Gerais do CEFIEP (Conselho dos Estudantes de Educação Física).

Glauber César Cruz Custódio: Bacharel e Licenciado em Educação Física pela Universidade Federal de Ouro Preto.

Recebido em setembro de 2015.

Aprovado em fevereiro de 2016.
VAGO, T. M. O "esporte na escola" e o "esporte da escola": da negação radical para uma relação de tensão permanente um diálogo com Valter Bracht. Revista Movimento, Rio Grande so Sul, v. 3, n. 5, abril/1996.

VEENMAN, S. Perceived problems of beginning teachers. Review of Educational Research, Los Angeles, EUA, 52(2) 143-178. (1984).

ZEICHNER, K. M. Políticas de formação de professores nos Estados Unidos: como elas afetam vários países do mundo. Belo Horizonte: Autêntica, 2013. 